\title{
SYMPATHETIC BLOCKADE OF ISOLATED LIMBS BY INTRAVENOUS GUANETHIDINE
}

\author{
A.J.C. Holland, K.H. Davies, and D.H. Wallace
}

AN ARTICLE by J.G. Hannington Kiff, ${ }^{1}$ describing the use of intravenous guanethidine for regional sympathetic blockade first aroused the interest of the authors in the clinical use of this substance.

During the last eighteen months, intravenous guanethidine has been used by members of the Anaesthetic Department of the Montreal General Hospital in a number of disease states, and, as a result, enough experience has been obtained with the drug to attempt to offer a few suggestions for its rational use in clinical situations.

\section{Pharmacology of Guanethidine}

Guanethidine is a drug which has very specific actions on the peripheral sympathetic nervous system. One method by which it produces sympathetic blockade is to inhibit response to sympathetic adrenergic nerve activity by blocking the release of catechol amines normally produced by nerve stimulation.? Probably its more important action, however, is to act as a substrate for the pump that produces active transportation of nor-adrenalin into the nerve endings. ${ }^{3}$ Once within the adrenergic neuron, guanethidine is taken up by nor-adrenalin storage vesicles and releases nor-adrenalin from the nerve ending. ${ }^{4}$ Such release of noradrenalin may produce transient hypertension if large amounts of guanethidine are given intravenously, followed by prolonged hypotension. ${ }^{5}$

Another property of guanethidine which is not as useful or desirable, and may also lead to hypertension, is that it sensitizes the effector cells to exogenous catechol amines. Although we have had no problems in this respect, it probably means that guanethidine, even when injected into an isolated limb, would be contraindicated in a patient with pheochromocytoma.

\section{METHOD}

All the patients who received intravenous guanethidine were managed in essentially the same fashion. The limb to be blocked was elevated from three to five minutes for drainage of blood, further exsanguinated by means of an Esmarch's bandage, and then a double cuff tourniquet, applied at either upper arm or thigh level, was inflated to a pressure approximately 50 Torr (arm), or 100 Torr (leg), greater than the systolic pressure. Through an intravenous needle which had been previously inserted into a peripheral vein of the limb to be blocked, a dose of 15 to $20 \mathrm{mg}$ (in the arm) or 20 to $30 \mathrm{mg}$ (in the leg) of guanethidine was injected.

From the Department of Anaesthesia, Montreal General Hospital, Montreal, Quebec. 


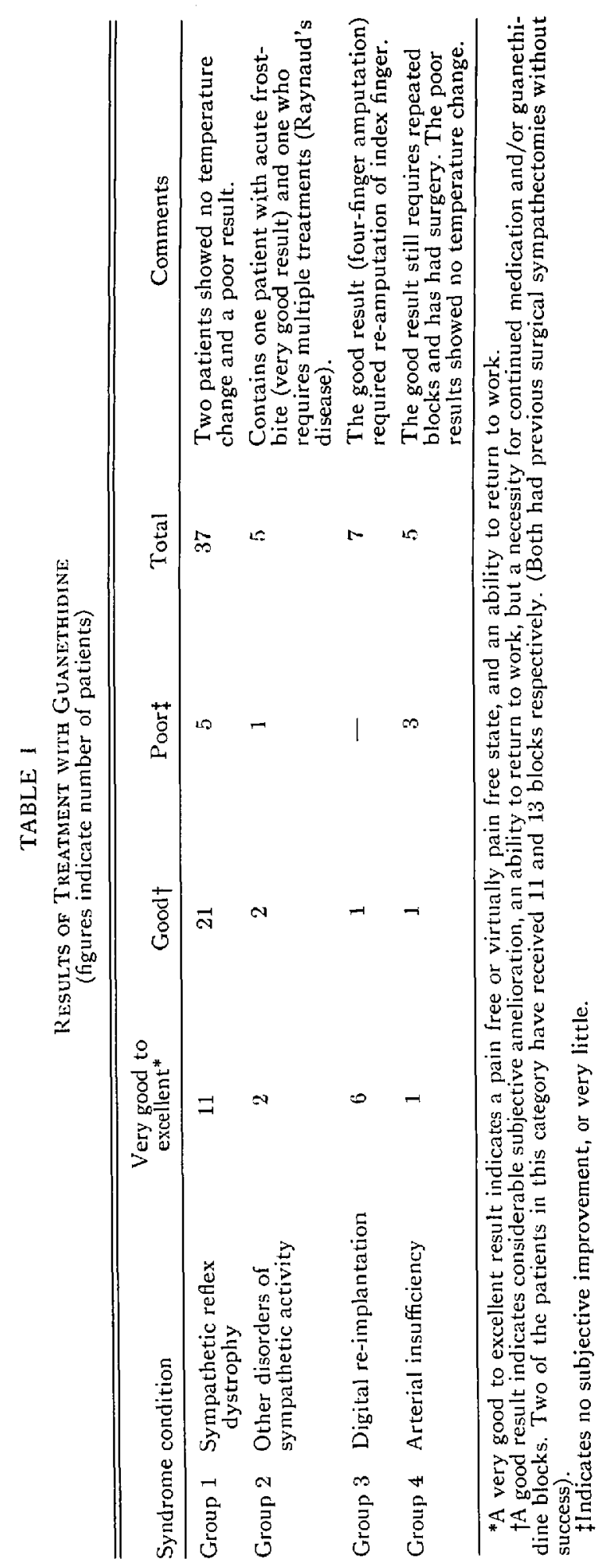


The guanethidine was diluted with $20 \mathrm{cc}$ ( $\mathrm{arm}$ ) to $40 \mathrm{cc}$ (leg) of normal saline solution or 0.5 per cent mepivacaine, depending on the limb that was to be blocked, and the size of the patient. The total dose and volume of drugs injected could be reduced by one-half if, for example, just the hand were isolated. The tourniquet was kept inflated for 15 minutes after injections in order to allow the guanethidine to fix properly, and to reduce any tendency towards hypotension on the release of guanethidine into the circulation when the tourniquet was deflated. If for any reason the circulation of the limb to be blocked was in jeopardy, the time of inflation of the cuff could be reduced to ten minutes. The patient was monitored in the Recovery Room for two hours after the block.

The efficacy of sympathetic blockade was adjudged by measuring the skin temperature with a thermistor thermometer. The measurements were made over the ulnar styloid process or the lateral malleolus and the temperatures of the blocked and unblocked limbs were compared, before and after administration of guanethidine. Those patients who could be followed-up on a long-term basis had temperature measurements every day or second day for a period of two weeks. All patients showed transient limb flushing which could have been easily explained as a result of reactive hyperaemia, and therefore the post-block temperature measurement was always made one hour after deflation of the cuff. The sole criterion used to adjudge the efficacy of sympathetic blockade (as distinct from success of the treatment) was a rise in temperature of $2^{\circ} \mathrm{C}$ or greater following blockade of the limb.

\section{RESULTS}

Patients on whom the procedure of Intravenous Guanethidine Blockade was performed fell into four main groups, and are summarized in Table I.

\section{Group 1. Reflex Sympathetic Dystrophies}

Reflex sympathetic dystrophy is a general term used to describe a number of syndromes in which the main aetiological factor seems to be a disorder of sympathetic nervous system conduction; it often follows trauma and is frequently characterized by burning pain, hyperaesthesia, and skin discolouration." Only when these three signs were present, was the reflex sympathetic dystrophy re-diagnosed as causalgia.

\section{Group 2.Other Diseases}

There are a number of disorders such as Raynaud's disease, frost-bite, and rheumatism with myalgia, in which disturbances of reflex sympathetic activity seem to be a prominent feature. Although not classified with the reflex sympathetic dystrophies, these conditions are often ameliorated by a sympathetic block and therefore formed a group in which guanethidine could be expected to have good results.

\section{Group 3. Digital Re-implantation}

This group of people were undergoing re-implantation or trans-plantation of severed digits, and they form the subject of a separate paper, ${ }^{\top}$ in which their management with intravenous guanethidine has been described. 
It has always been a problem in such patients to maintain an adequate circulation to the implanted digit or digits, and both cervical and sympathetic blockade and anticoagulant therapy have been advocated to ensure a good circulation and to reduce the risk of vasospasm. ${ }^{\mathrm{s}-10}$

Anticoagulant régimes differ widely. Most of them, however, tend to be variants on a theme of dextran (either low or high molecular weight), heparin, in doses varying from 5,000 units to 25,000 units per day, aspirin, 1.0 gm daily or dipyridamole $25 \mathrm{mg}$ four times daily. Antibiotics are universally used, the limb is in general kept elevated, although movement is encouraged and therapy is continued for 10 to 14 days. ${ }^{0,10}$

Four patients at the Montreal General Hospital have now been blocked with guanethidine prior to digital re-implantation and, although it is difficult to be specific, there is a strong clinical impression that each of these patients has done better than he would have if he had not been blocked. In only one patient with a four finger amputation was further amputation necessary because of gangrene.

\section{Group 4. Arterial Insufficiency}

In several patients with arterial insufficiency of the lower limb, lumbar sympathectomy was considered as a means of treating the ischaemic pain. A normal sympathetic blockade with local anaesthetic agents would not last long enough to establish the value of sympathectomy. The long duration of guanethidine blockade was of value in such patients to assess whether or not sympathectomy would be of benefit.

\section{Diagnostic}

Because of the tendency of guanethidine to displace noradrenalin from storage sites, it could be expected that those patients in whom the diagnosis of causalgia was entertained would possibly suffer from an exacerbation of their pain upon injection of guanethidine.

Four patients out of five who received intravenous guanethidine diluted only with saline for causalgic pain in the hand did, in fact, show quite severe exacerbation of their pain immediately upon injection. After this, guanethidine diluted with local anaesthetic solution was used for the added comfort that such a mixture provided the patient, even though more than half the patients who received such a mixture still complained of transient increase in pain.

\section{Discussion}

Although the number of patients that are treated with intravenous guanethidine in any one department per year is rather small, nevertheless a number of trends are clearly discernible. If a diagnosis of sympathetic dystrophy is uncertain, a sympathetic block with local anaesthetic could be undertaken. If this was successful, then, rather than a series of similar blocks as advocated by some, ${ }^{8}$ a single guanethidine block would be performed. 
Although the majority of patients have blocks involving the arm, intravenous regional sympathetic blockade with guanethidine is a technique which can be used with equal ease in the leg.

Though it is impossible to give an objective and quantitative opinion concerning the best method for improving circulation in implantation surgery, nevertheless there is a distinct impression that the patients who received guanethidine therapy did better post-operatively than those who did not receive such therapy.

\section{Conclusion}

A number of patients have received intravenous guanethidine sympathetic blockade of extremities during a 12 -month period. The conclusion of $\mathrm{J}$. Hannington Kiff $^{1}$ that this technique provides a simple and efficient means of producing longterm sympathetic blockade has been confirmed.

\section{SUMMARY}

As a result of experience at the Montreal General Hospital, it has been found that intravenous guanethidine blockade of extremities has therapeutic, prophylactic and diagnostic value in conditions where the aetiology is a disorder of sympathetic nervous conduction.

The properties of guanethidine, namely its selective action on blocking the sympathetic nervous system peripherally, together with its long half time and rapid tissue fixation, render it a very useful drug in techniques where an isolated limb is blocked with guanethidine.

Experience on an 18-month basis suggests that the procedure of intravenous guanethidine blockade offers exceptionally good results for a non-invasive technique.

Work is now in progress to study the possible use of guanethidine in the treatment of phantom limb pain, and also to see whether other drugs, such as thymoxamine, could be used in a similar fashion to guanethidine.

\section{RÉSUMÉ}

Les auteurs revoient la pharmacologie de la guanethidine et discutent de son usage intraveineux pour la production de blocs sympathiques au niveau des membres supérieurs et inférieurs.

Une manchette double esț utilisée pour isoler le membre avant l'injection intraveineuse et reste gonflée 15 minutes après l'injection pour permettre la fixation de l'agent.

Les auteurs considèrent que cet agent peut être utilisé pour la production de blocs sympathiques à des fins thérapeutiques, prognostiques ou diagnostiques. Cette technique est sécuritaire, simple et efficace si elle est effectuée telle que décrite. 


\section{REFERENCES}

1. HANNINGTON KIFF, J,G, Intravenous sympathetic blockade with guanethidine. Lancet 1: 1019 (1974).

2. Goodman, A. \& Gillman, L.S. The pharmacological basis of therapeutics, Fifth edition, New York: Macmillan (1975).

3. Freis, E.D. Guanethidine. Prog. Cardiovasc. Disease 8: 183 (1965).

4. Chanc, C.C., Costa, E., \& Bromie, B.B. J. Pharmac. Exp. Ther. 147: 303 (1965).

5. WoosLey, R.L. \& Nics, A.S. Drug therapy: guanethidine, New England Journal of Medicine 295: 1053 (1976).

6. Menta, M. Intractable pain. London: Saunders (1973).

7. Davies, K.H. Guanethidine sympathetic blockade: its value in re-implantation surgery. British Medical Journal 1: 876 (1976).

8. Komatsu, S. \& Tamai, S. Successful re-implantation of a completely cut-off thumb. Plastic and Reconstructive Surgery 42:374 (1968).

9. O'BRiEN, B. MCC. Re-implantation and reconstructive microvascular surgery, part I. Ann. Royal College of Surgeons of England 58: 87 (1976).

10. Ixuta, Y. Microvascular Surgery. Hiroshima, Lens Press Company (1975). 